\section{Education and Consumer Informatics}

\author{
C. Boyer, Section Editor for the IMIA Yearbook Section on Education and Consumer Informatics \\ Health On the Net Foundation (HON), Geneva, Switzerland
}

\section{Best Paper Selection}

The selected best papers discuss how the general public accesses the Internet for health information, giving a general overview of the different manners and reasons that health information is accessed, according to age groups and other variables.

Laurent and Vickers investigate the popularity of Wikipedia compared to established quality health websites such as Medline Plus and NHS Direct Online. Wikipedia is, in fact, a very popular source of health information for the general public, ranking among the first ten results $71-85 \%$ of the time, above both Medline Plus and NHS Direct Online.

Zhao compares online health information access by teenagers in different socio-economic levels showing that a large fraction of poorer teenagers, unlike their richer counterparts, access the Internet for their parents who are not Internet savvy.

Britto et al. studied the usability of various paediatric information websites using a group of parents with children having chronic diseases.

Taha et al. discuss and explore online health information access by older citizens and compare it to conventional health information gathering from books and journals.

\section{Conclusions and Outlook}

The papers selected show the reader the many facets of accessible online health information, such as the varying types of persons who access it and their reasons for doing so.
The Internet is now recognizably one of the greatest information resources. Learning more about who access the Internet and why would help to greatly improve the Internet, enabling a 'tailor-made' fit for everyone

Correspondence to:

Celia Boyer

Health On the Net Foundation (HON)

81 bd de la cluse

1205 Geneva, Switzerland

E-mail: celia.boyer@healthonnet.org

\section{Appendix: Content Summa-} ries of Selected Best Papers for the IMIA Yearbook 2010, Section Education and Consumer Informatics*

\section{Laurent MR, Vickers TJ \\ Seeking health information online: does Wikipedia matter? \\ J Am Med Inform Assoc 2009;16:471-9}

This paper measures the popularity of Wikipedia over already established quality online health information websites such as the Medline Plus and NHS Direct. General Internet search engines such as Google, Yahoo and MSN were used. 1726 keywords were chosen from the Medline health topic index, they included the titles of all MedlinePlus Health Encyclopedia entries, common synonyms (such as Hy

* The complete papers can be accessed in the Yearbook's full electronic version, provided that permission has been granted by the copyright holder(s) 
Table 1 Best paper selection of articles for the IMIA Yearbook of Medical Informatics 2010 in the section 'Education and Consumer Informatics'. The articles are listed in alphabetical order of the first author's surname.

\section{Section}

Education and Consumer Informatics

- Britto MT, Jimison HB, Knopf Munafo J, Wissman J, Rogers ML, Hersh W. Usability testing finds problems for novice users of pediatric portals. J Am Med Inform Assoc 2009;16:660-9.

- Laurent MR, Vickers TJ. Seeking health information online: does Wikipedia matter?.J Am Med Inform Assoc 2009;16:471-9.

- Taha J, Sharit J, Gzaja S. Use of and satisfaction with sources of health information among older internet users and nonusers. Gerontologist 2009;49:663-7.

- Zhao S. Parental education and children's online health information seeking: Beyond the digital divide debate. Soc Sci Med 2009;69:1501-10.

pertension and High blood pressure), search terms and abbreviations (such as Multiple Sclerosis and MS). These keywords were mainly in American English. Similarly, 966 keywords in the online alphabetical topic index of NHS Direct Online were chosen, these words being in British English, including specifically British terms such as A\&E (Accident and Emergency). 1,173 keywords from the online alphabetical index of the US National Organization of Rare Diseases (NORD) were also extracted. These keywords did not comprise only of terms of rare diseases but also contained commonly used terms such as cataract, colon cancer, prostate cancer, etc.

Articles on Wikipedia were classified according to quality, and higher quality articles were chosen. The investigators then looked for the previously chosen keywords in the higher quality Wikipedia articles.

Using a search engine optimization tool, they investigated the results which were brought forward and found that Wikipedia was more commonly listed by Google than Medline Plus and NHS Direct, even when the search terms originated from those websites.

The authors conclude that Wikipedia is extremely popular with the public as a source of health information, even though most of the website contains unreferenced information, demonstrating that the public in general does not place too much importance to quality health information.

\section{Zhaos}

Parental education and children's online health information seeking: Beyond the digital divide debate

\section{Soc Sci Med 2009;69:1501-10}

This paper investigates online health information retrieval by teenagers in both high and low socioeconomic strata. Various factors have been identified for the difference in Internet access, including logistical difficulty in accessing the Internet by poorer users who may have to use dial-up connections and slower Internet speeds.

Parental education has previously been thought to affect teenage online health information access, resulting in less time online looking for health information by teenagers with less-educounterparts. This study set out to find out more information regarding this. The survey was conducted by studying 2004 and 2006 Pew Internet and American Life Project surveys. The paper concludes that this survey shows that there are indeed differences between the online health information access by teenagers from lower and higher socioeconomic backgrounds. Teens from higher education backgrounds mainly access the Internet via broadband connections within their own homes while teens from lower education backgrounds access the Internet from school or other public place using a dial-up modem. cated parents, compared to their richer
Low parental education is thought to result in less online access by their children. However, this study shows that in fact, there is an increase of online health information access by teens whose parents are poorly educated. It is hypothesized that this could be compensation for by other factors such as greater online access by teenagers who are looking for health information for their less educated parents. The authors also conclude that the Internet helps impoverished teens by allowing them better benefits than their less educated parents. Finally, authors conclude that although the frequency of health information access may be similar, the quality of the search may not be equal, thus proposing an eHealth literacy program for poorer teens to teach them efficient online health information retrieval.

\section{Taha J, Sharit J, Czaja S}

Use of and satisfaction with sources of health information among older internet users and nonusers

\section{Gerontologist 2009;49:663-7}

This paper discusses health information needs of older adults and explores various possible ways they could retrieve information. The investigators gathered participants between the ages 51 - 85 years and divided them into 2 groups: Internet group (those who visited the Internet frequently (might be useful to say how often 'frequent' means) to gather health information) and non-Internet group (those who did not use or rarely use the Internet for information). Each group was divided into focus groups of 5 to 8 participants and semi-structured interviews carried out to find out some general demographic information, technical knowledge about computers and the Internet and information regarding the health information sources used. Following this, the participants were asked to discuss various topics such as why they looked for health information and if they looked for it before or after a doc- 
tor's visit, satisfaction with health information found/given etc. The data collected was analysed using the grounded theory approach. Investigators found that reasons for users to search for health information included looking up health information for them or for a relative/loved one and to maintain general good health. Both the Internet users and non-Internet users had searched for information prior to a doctor's visit. Both users agreed that there are pros and cons to the Internet. The authors conclude that the main findings of this study was that Internet users felt more empowered and confident regarding their healthcare than non-Internet users, and go on to state that the use of the Internet to help senior citizens become educated health care consumers is important and should be pursued wherever possible.

\section{Britto MT, Jimison HB, Knopf Munafo J, Wissman J, Rogers ML, Hersh W \\ Usability testing finds problems for novice users of pediatric portals}

\section{J Am Med Inform Assoc 2009; 16:660-9}

This paper discusses the usability of paediatric health information portals for the use of parents with children suffering from chronic illnesses. 16 sets of parents were chosen, their children were sufferers of Juvenile Idiopathic Arthritis, Diabetes Mellitus or Cystic Fibrosis. Information regarding their computer literacy, time spent at the computer and familiarity with their child's condition was taken. They were then provided prototype portals which were specific to their children's disease. Audio and Video recordings were then taken of the participants while they accessed each portal from a laptop. Tasks were allocated and participants were asked to 'think aloud' when attempting these tasks. Following testing, participants completed a Computer Usability Satisfaction Questionnaire which included 19 items related to efficiency, ease of use, and likeability of the system interface. Participants responded on a Likert and could also respond in their own words.

The results showed that there were in fact no significant differences among groups regarding familiarity with the child's condition, computer knowledge and use, participant age, duration since diagnosis of the disease.

The authors conclude that though the participants encountered several difficulties including portal navigation and task completion, most of them reported positive perceptions of the system. 